\title{
Vibration produced by hand-held olive electrical harvesters
}

\author{
Emanuele Cerruto, Giuseppe Manetto, Giampaolo Schillaci \\ Section of Mechanics and Mechanisation, Department of Agri-food and Environmental Systems \\ Management (DiGeSA), University of Catania, Catania, Italy
}

\begin{abstract}
The paper reports the results of some laboratory and field tests aimed at assessing the acceleration levels transmitted to the hand-arm system by electric portable harvesters for olive. Four harvesting heads, different for shape and kinematic system, and five bars, different for diameter, length and material (aluminium and carbon fibre), were used in assembling eleven harvesters. The vibrations were measured in two points, next to the handgrips. The laboratory tests allowed the evaluation of the acceleration levels in standard controlled conditions, while the field tests allowed the assessing of the effects of the tree canopy with respect to the no load running. The laboratory tests showed that in reducing the vibration level plays a major role the kinematic system of the harvesting head and then the bar material. The classical flap-type harvester produced accelerations of around $20 \mathrm{~m} / \mathrm{s}^{2}$, while by using a harvesting head with two parts in opposite movement, the accelerations were lowered to about $6 \mathrm{~m} / \mathrm{s}^{2}$. The use of carbon fibres for the bars, besides the reduction in weight, produced also a reduction in acceleration (from 21 to $16 \mathrm{~m} / \mathrm{s}^{2}$ ). The field tests proved that the tree canopy had a negative effect on the vibrations transmitted to the hand-arm system, especially when the aluminium bar of small diameter was used.
\end{abstract}

\section{Introduction}

Italy is among the major producers of olive oil in the Mediterranean basin, alongside Spain, Greece and Turkey (FAO, 2010). The main figures of the Italian olive growing are: 1,190,000 ha of cultivated surface, mainly concentrated in the Centre-South of the peninsula, 3,400,000 $t$ of olives and 513,000 $t$ of oil (ISTAT, 2010). The Italian oil is on average about a fifth of the oil yearly produced all over the world (IOC, 2011). Moreover, Italy is both a big importer and exporter of olive oil: in 2010 they were imported $610,000 \mathrm{t}$, to the value of 1.20 billion of Euros, and exported 380,000 t, to the value of 1.17 billion of Euros (ISMEA, 2012).

Even so, due to some aspects related to production costs and market force dynamics, the Italian olive oil sector is going through a ticklish moment. Income maintenance and quality preservation require, among other things, a reduction of production costs. Drupe harvesting is the most expensive phase of the olive production, mainly when full mechanisation is not possible due to several factors as farm fragmentation (in Sicily, 70 percent of farms are smaller than 2 ha), tree structure, irregular tree layout, and sloping lands. In these cases the use of hand-held vibrating tools, approximately capable of triplicate the productivity of the workers with respect to the manual harvesting, is taken into great consideration (Famiani et al., 2008).

Unfortunately, the increase in the mechanisation level has introduced additional sources of risk for operators. In fact, since their appearance in the market, these tools have been characterised by lack of comfort due to the quite high levels of noise and vibration, as well as to the fatigue caused by the weight (Iannicelli and Ragni, 1994; Blandini et al., 1997; Caruso et al., 2005; Deboli et al., 2008; Pascuzzi et al., 2008). These aspects are often underestimated by users, mainly interested in the gain of productivity.

Vibration is probably the most important risk connected with the use of these portable harvesters and can be reduced after proper design or optimal selection of the operating parameters (Monarca et al., 2007; Pascuzzi et al., 2008; Mallick, 2010). Workers, when operate with hand-held power tools, in most of the cases do not perceive acceleration levels as being too high, so increasing the exposure risk (Vergara et al., 2008). Vibration on the hand-harm system can lead to chronic disorders known as Raynaud syndrome, or vibration white finger, or dead finger, a disease which shows itself after a latency period and which demands attention from all the medical personnel (Chetter et al., 1998). Disorders are reversible if vibration exposure is reduced or eliminated (Ramos et al., 1996; Griffin, 2008).

The biodynamic response of the hand-arm system is affected by several factors, among which acceleration level, vibration direction, frequency, posture, grip force, operating tool, mechanical impedance and handle features can be cited (Buström, 1997; Monarca et al., 2003; Dong et al., 2004; Aldien et al., 2006; Besa et al., 2007; Deboli et al., 2008; Dewangan and Tewari, 2008; Concettoni and Griffin, 2009). Moreover, some of these factors are correlated with the effectiveness 
of anti-vibrating gloves, which can be used to reduce vibration exposure for operators (Dong et al., 2005), so reducing at the same time the work stress (Tewari and Dewangan, 2009).

To increase operator's comfort and to try to respect the threshold limit values imposed by the recent regulations (European Commission, 2002; Italian Regulation, 2005, 2008), many makers have marketed for some years, together with the usual pneumatic or mechanic models, portable harvesters powered by electric motors, characterised by greater lightness, greater handiness and which resulted very effective in reducing the noise level with respect to those powered by two-stroke engines (Biocca et al., 2008).

The development of these new tools has involved changes in shape and dynamics of the harvesting system, as well as in the material for their construction (introduction of carbon fibres to reduce the weight). These changes may affect the accelerations transmitted to the workers during their use, so different levels of vibration may be expected (Çakmak et al., 2011) and the agreement with the current regulations must be verified.

Based on the results of previous works (Cerrulo et al., 2010; Cerruto et al., 2011), this research aims to evaluate the vibrations transmitted to the hand-arm system by different electric portable harvesters at varying bar features (material, length and diameter), dynamic of the harvesting head, and operating conditions (in laboratory, at no load, and in field, under ordinary working conditions).

\section{Materials and methods}

\section{The portable harvesters}

Experimental tests were carried out by using electric portable harvesters produced by a local manufacturer. Four harvesting heads were considered, different for number and arrangement of the teeth (the small bars that beat branches and olives during the harvest), as well as for direction of the oscillations (Figure 1). All the teeth are in carbon fibres and of the same size (diameter $=5 \mathrm{~mm}$, length $=370 \mathrm{~mm}$ ).

More in detail, the harvesting heads $\mathrm{H} 1, \mathrm{H} 2$ and $\mathrm{H} 3$ present an aluminium-made box and the same mechanism to activate the teeth. The teeth are connected to a $36-\mathrm{cm}$ main arm that in $\mathrm{H} 1$ and $\mathrm{H} 2$ is disposed orthogonally to the motor shaft, while in $\mathrm{H} 3$ is disposed parallel, so the oscillating planes are orthogonal. The harvesting heads $\mathrm{H} 1$ and the $\mathrm{H} 2$ carry 8 teeth with different arrangement, while $\mathrm{H} 312$, arranged in the classical flap-type shape, widely used in pneumatic models. Users can assemble the three heads by modifying number and position of the teeth according to their needs.

The harvesting head H4 has a plastic-made box to which are connected two arms with opposed oscillations on a plane orthogonal to the motor shaft. Each arm carries 4 teeth.

The harvesting heads $\mathrm{H} 1, \mathrm{H} 2$ and $\mathrm{H} 3$ are merchandised with bars different for material (aluminium and carbon fibres), diameter (35 and 40 $\mathrm{mm}$ ), and length ( 2010 and $2210 \mathrm{~mm}$ ), but with the same thickness (2 $\mathrm{mm}$ ), while $\mathrm{H} 4$ is marketed only with an aluminium telescopic bar, 1 mm thick, diameters of 28 and $35 \mathrm{~mm}$, and lengths of 2060 (minimum) and $2850 \mathrm{~mm}$ (maximum).

The main features of harvesting heads and bars are reported in Table 1.

The electric motor (maximum power of $900 \mathrm{~W}$ and rotating speed of around $6000 \mathrm{rpm}$, fixed by an electronic card), of the same type for all the harvesters tested, is feed by means of an external $12 \mathrm{~V} \mathrm{DC}$ battery; the electric cable is placed inside the bar, from which it emerges near the handgrip equipped with the activation switch. The motor shaft is connected to a box that, with a gear ratio of 10:58, gets the arms with the teeth moving with oscillating frequency of $18 \mathrm{~Hz}$.

\section{Vibration measurement}

The laboratory and field tests were conducted in different stages: firstly the laboratory tests and then the field ones.

The three harvesting heads $\mathrm{H} 1, \mathrm{H} 2$ and $\mathrm{H} 3$ were tested with the three bars B1, B2 and B3, according to a full factorial experimental design, while $\mathrm{H} 4$ was tested with the telescopic bar B4/B5 only. By comparing the bars B2 and B3, it was possible to evaluate the effect of the material (aluminium and carbon fibres) on the vibrations, while by comparing the bars B1 and B3, the effects of diameter (35 and $40 \mathrm{~mm}$ ) and length (2010 and $2210 \mathrm{~mm}$ ) were evaluated. Finally, the study of the harvester $\mathrm{H} 4$ allowed the assessment of a completely different dynamic system.

During laboratory tests, to smooth the influence of external factors, the harvesters were used by the same person. The tests were carried out by fixing the angle of the bar according to three directions, so to cover all the possible orientations assumed during the working activity: vertical, inclined at about $45^{\circ}$ and horizontal. Furthermore, vibrations were measured, at different times, in two points (MP1 and MP2) for each bar, at the grip level for both hands of the operator (Figure 2). Their position was fixed by observing the operator in standard working condition.

Table 1. Main features of bars and harvesting heads.

\begin{tabular}{lcccc} 
& \multicolumn{4}{c}{ Bars } \\
Material & Bl & CF & Al & Al \\
Diameter, mm & 35 & 40 & 40 & $35 / 28$ \\
\hline Thickness, mm & 2 & 2 & 2 & 1 \\
Length, mm & 2010 & 2210 & 2210 & $2060 / 2850$ \\
\hline Mass, kg & 1.356 & 1.342 & 1.416 & 1.650 \\
& & & & \\
& H1 & H2 2 & H3 & H4 \\
Teeth & 8 & 8 & 12 & 8 \\
Mass, $\mathrm{kg}$ & 1.545 & 1.545 & 1.365 & 1.250 \\
\hline
\end{tabular}

Al, aluminium; CF, carbon fibres; B, bar; $\mathrm{H}$, head.

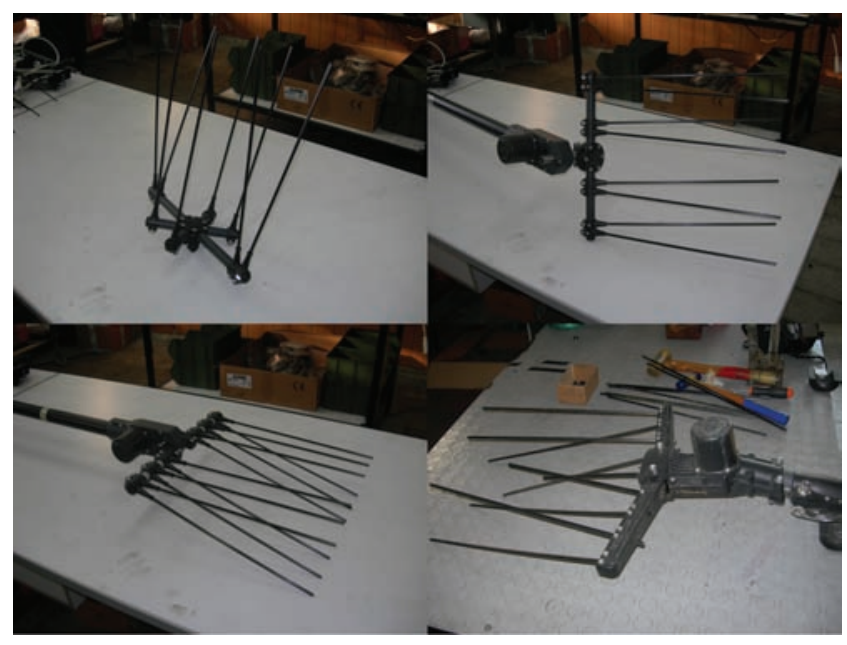

Figure 1. Harvesting heads (from H1, top left, to H4, bottom right). 
Overall, 66 measurement sessions [ $(3$ harvesting heads $\times 3$ bars + $\mathrm{H} 4$ harvesting head $\times 2$ bars $) \times 3$ inclinations $\times 2$ measurement points] were carried out, each lasting at least $5 \mathrm{~min}$.

The field tests were carried out in an olive-yard with irregular spacing and olive of variety Nocellara Etnea, pruned according to the vase method and having an average tree crown diameter of about $4 \mathrm{~m}$. As a first study, only the $\mathrm{H} 3$ harvesting head, applied to the three bars B1, B2 and B3, was tested. Again, vibrations were measured in two points on the bar as during the laboratory tests. To allow the ordinary working conditions, the bar inclination should be continually changed and therefore it was not considered as a factor, so other 6 measurement sessions were carried out. The measurement time for the different configurations ranged from about 4 to $13 \mathrm{~min}$, so to complete the harvesting of one tree during each run (Figure 3 ). This variability was due to the high differences among the tree yield. The harvesters were operated by the same person, but for practical reasons, different by that one which worked during the laboratory tests. This could affect the comparison between laboratory and field tests, but nevertheless allows carrying out a first evaluation of the canopy effects.

Accelerations were measured by using three mono axial accelerometers DJB, model A/123/S (DJB Instruments Ltd., Suffolk, UK), screwed on the faces of a small cube tied to the bars with a metallic clamp, so to be equivalent to a triaxial accelerometer. The reference axes were selected according to the basicentric coordinate system defined by the UNI EN ISO 5349-1:2004 regulation (IS0, 2004): $x$-axis perpendicular to the palm surface area, $y$-axis parallel to the longitudinal axis of the grip, and $z$-axis directed along the third metacarpus bone of the hand (Figure 4).

During the laboratory tests, the signals of the accelerometers were amplified by means of three amplifiers MESA, model C24 (SCS Controlli e Sistemi srl, Padova, ltaly), and then recorded on digital tapes by means of a four channel digital audio tape recorder. Subsequently they were acquired in a PC by means of a $\mathrm{dB} 4$ four-channel acquisition unit and the recording module of the dBFA Suite software $(01 \mathrm{~dB}$ Metravib, Lyon, France). Instead, during the field tests, the signals were directly recorded on the hard disk of a notebook by means of the $\mathrm{dB} 4$ unit and the recording module of the dBFA Suite software (01dBMetravib).

Subsequently all the recorded signals were analysed by using the post-processing module of the dBFA Suite software (01dB-Metravib), that allows for several post-processing analyses, among which narrow band analysis (FFT), 1/3 octave analysis, and frequency weighting for the hand-arm system.

\section{Data analysis}

According to the UNI EN ISO 5349-1:2004 regulation (ISO, 2004), signal analysis was performed in the range $5.6-1400 \mathrm{~Hz}$ (third of octave bands from 6.3 to $1250 \mathrm{~Hz}$ ) by applying the FFT and the 1/3 octave analysis. Being the maximum frequency of interest $1400 \mathrm{~Hz}$, a signal length of about $10 \mathrm{~s}$ is enough for the digital analysis. So, to have some replications useful for the statistical analysis and to evaluate the variability in time, sub-samples of 1 min were extracted from each acceleration signal recorded during the measurement sessions. The number of sub-samples was equal to 4 for the laboratory tests and ranged from 4 up to 13 for the field tests due the different length of the acquisition time. The frequency weighted root mean square (RMS) accelerations were computed for each axis $\left(a_{h w z}, a_{h w y}\right.$, and $\left.a_{h w z}\right)$ and then the global weighted acceleration $a_{h w}$ was calculated as:

$$
a_{h w}=\sqrt{a_{h w x}^{2}+a_{h w y}^{2}+a_{h w z}^{2}}
$$

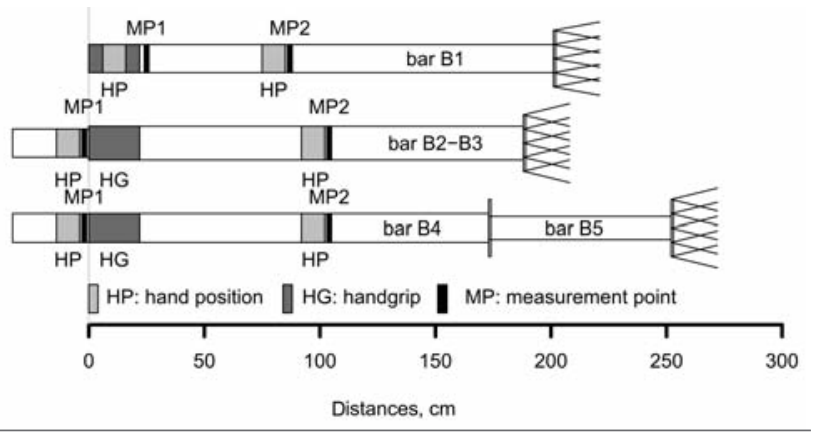

Figure 2. Schematic view of harvesters and measurement points (MP1 and MP2).

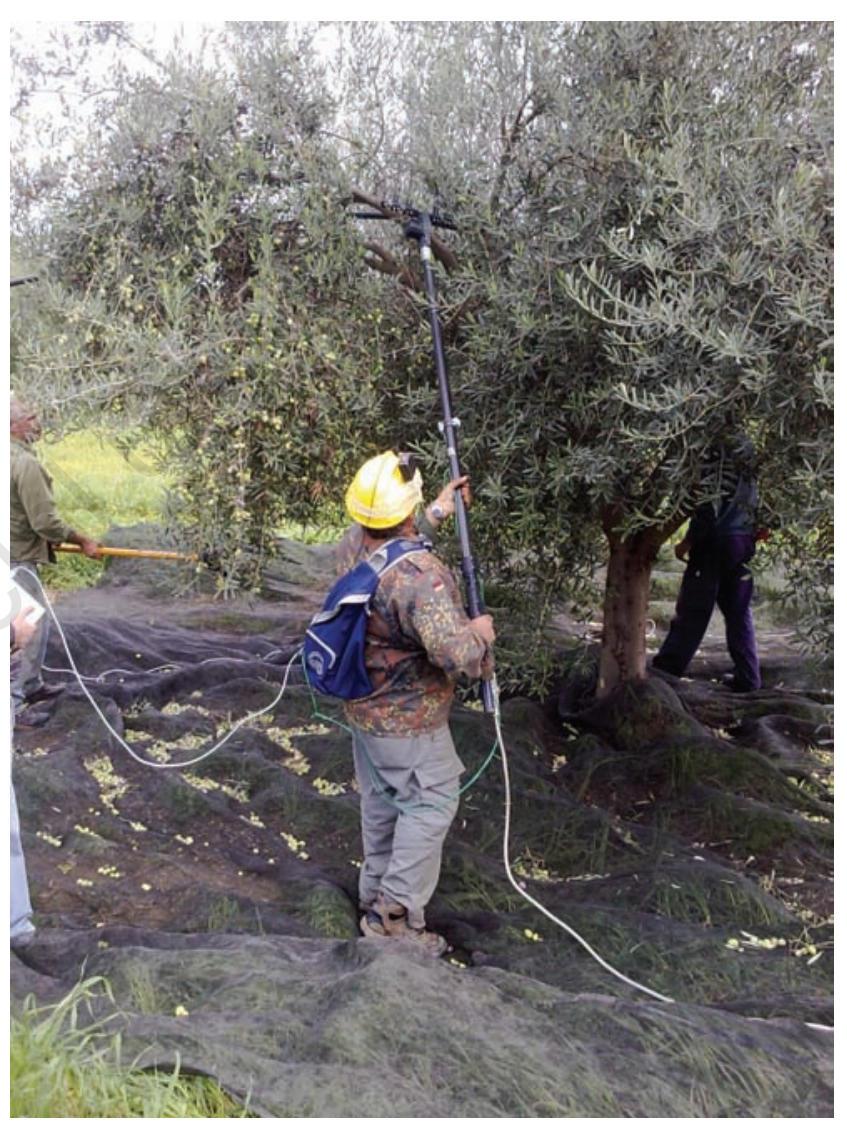

Figure 3. Olive harvesting with the portable harvesters.
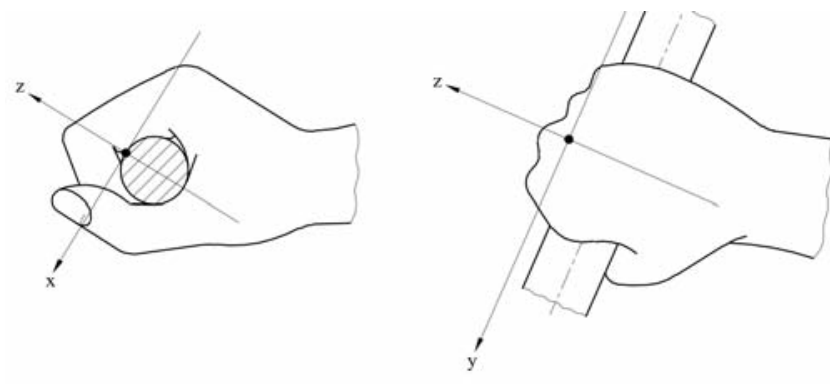

Figure 4. Reference axes for vibration measurement. 
Finally, the daily vibration exposure value, $A(8)$, standardized to an 8-h reference period, was obtained:

$$
A(8)=\sqrt{\frac{T}{T_{0}}} a_{h w}
$$

being $T_{0}=8 \mathrm{~h}$ and $T$ the daily exposure time (h).

The $A(8)$ values were compared with the daily exposure action value of $2.5 \mathrm{~m} / \mathrm{s}^{2}$ and the daily exposure limit value of $5.0 \mathrm{~m} / \mathrm{s}^{2}$ established by the European Directive 2002/44/EC (European Commission, 2002).

RMS values were statistically analysed to detect significant differences related to bar type, harvesting head and working conditions (laboratory $v$ field tests). All computations and graphical representations were performed by means of the open source software $R$ (R Development Core Team, 2009).

\section{Results and discussion}

\section{Laboratory tests}

The analyses were carried out on the weighted global acceleration values. Given the experimental design, as a first approach the interaction bar $\times$ harvesting head was treated as a single factor, to compare the harvesting head $\mathrm{H} 4 v s$ the other ones and to evaluate the effects of bar angle and measurement point on the vibrations. The results are summarised in Figure 5.

It allows for the following observations:

- the harvesting head H4 produces vibrations much lower than the other ones;

- the differences between the two bars B4 and B5 when used with the harvesting head $\mathrm{H} 4$ seem to be not statistically significant;

- the differences among the three bar angles seem to be not statistically significant;

- the mean value of the global acceleration in the measurement point MP2 is greater than that measured in MP1.

Being the distribution of the global acceleration values not normal and not being possible to normalise it after the usual data transformations (P-level<0.001), the statistical comparisons were performed by applying the more robust Kruskal-Wallis non-parametric test rather than the analysis of variance. The results of the comparisons are reported in Table 2 and they confirm the observations derived from Figure 5.

The vibration level produced by the harvesting head $\mathrm{H} 4$ is much lower than that produced by the other ones (P-level<0.001): the opposite oscillations of the two arms allow for a partial compensation of the vibrations transmitted to the hand-harm system, whatever bar length and angle. This means that the vibration level is mainly affected by the kinematic system rather than the power source type (electric, mechanic or pneumatic). The acceleration measured in MP2 is greater than that measured in MP1 ( $\mathrm{P}$-level<0.001) probably because the measurement point MP2 is closer to the harvesting head, the source of the vibrations. The bar angle does not affect the vibration level (Plevel=0.172) transmitted to the hand-harm system, so guidelines to the users are unnecessary from this point of view. Finally, the differences in vibration level when using the harvesting head $\mathrm{H} 4$ with the telescopic bar at minimum (B4) or maximum (B5) length are not statistically significant.

All the measured values are reported in Figure 6, which visually confirms the results previously discussed and, in addition, shows that, in most cases, the variability among the 1-min sub-samples is rather moderate (only $\mathrm{H} 3$ presents great variability in MP2 when used with the bar
B1), meaning an almost constant level of exposure of the operator.

Subsequently, to study more in detail the effects of bar type and harvesting head, the nine combinations (bar B1, B2, B3 $\times$ head H1, H2, $\mathrm{H} 3$ ) were analysed separately as a full factorial experimental design. The results of the non-parametric tests are reported in Figure 7.

They show that the carbon fibre bar (B2) produces, on average, accelerations lower than the aluminium one (B3) with the same diameter and length. Moreover, the comparison carbon fibre $v s$ aluminium is statistically significant (P-level<0.001): 16.3 vs $21.1 \mathrm{~m} / \mathrm{s}^{2}$ (median

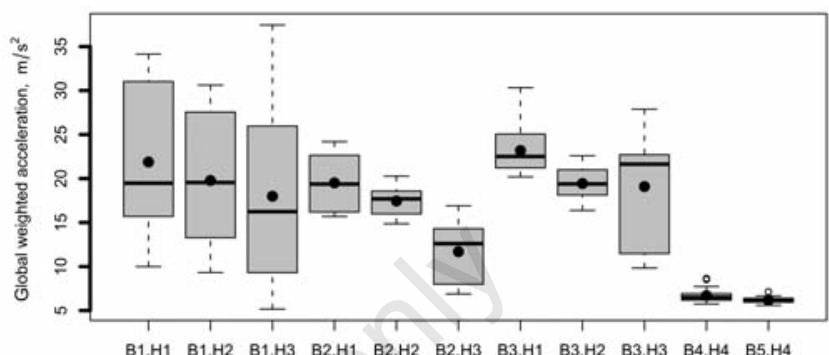

Bar type $\times$ harvesting head
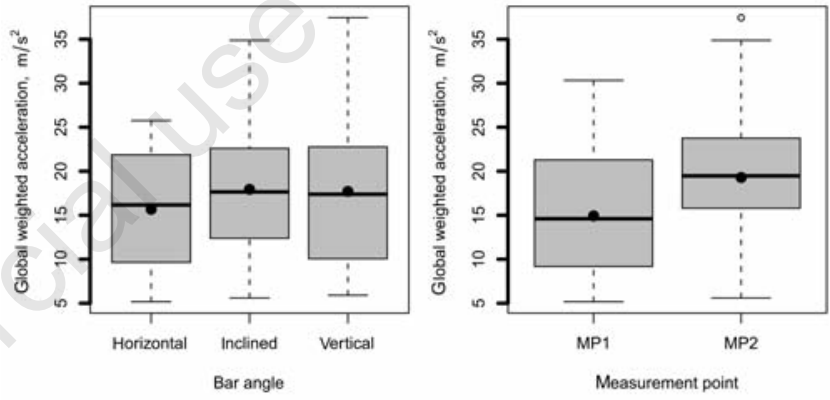

Figure 5. Box plot of global weighted acceleration at varying harvesting head, bar type, bar angle and measurement point; points represent mean values.

Table 2. Comparisons among the global weighted accelerations of the main factors.

\begin{tabular}{|c|c|c|}
\hline \multirow{2}{*}{\multicolumn{3}{|c|}{$\begin{array}{l}\text { Mean, } \mathrm{m} / \mathrm{s}^{2} \text { Harvesting heads } \\
\end{array}$}} \\
\hline & & \\
\hline $\mathrm{H} 1+\mathrm{H} 2+\mathrm{H} 3$ & $18.9^{\mathrm{a}}$ & $18.9^{\mathrm{a}}$ \\
\hline $\mathrm{H} 4$ & $16.4^{\mathrm{b}}$ & $16.3^{b}$ \\
\hline \multicolumn{3}{|c|}{ Measurement points } \\
\hline MP1 & $14.9^{b}$ & $14.6^{\mathrm{b}}$ \\
\hline MP2 & $19.3^{\mathrm{a}}$ & $19.5^{\mathrm{a}}$ \\
\hline \multicolumn{3}{|c|}{ Bar angles } \\
\hline Horizontal & $15.7 \mathrm{~ns}$ & $16.2 \mathrm{~ns}$ \\
\hline Inclined & $17.9 \mathrm{~ns}$ & $17.7 \mathrm{~ns}$ \\
\hline Vertical & $17.7 \mathrm{~ns}$ & $17.4 \mathrm{~ns}$ \\
\hline \multicolumn{3}{|c|}{ Bars B4 and B5 } \\
\hline B4-H4 & $6.7 \mathrm{~ns}$ & $6.5 \mathrm{~ns}$ \\
\hline B5-H4 & $6.2 \mathrm{~ns}$ & $6.1 \mathrm{~ns}$ \\
\hline
\end{tabular}

Group separation by Kruskal-Wallis test for P-level=0.05. H, head; MP, measurement point; B, bar; ns, not significant; a,bvalues having a common letter are not significantly different at P-level $=5 \%$. 
values). Carbon fibre, therefore, besides the reduction in weight, has also a positive effect in reducing the vibrations transmitted to the hand-harm system. The differences between the two aluminium bars (B1 vs B3) are instead not statistically significant.

The differences among the three harvesting heads are significant too: $\mathrm{H} 1$ produces the highest vibrations, $\mathrm{H} 3$ the lowest ones. The different disposition of the teeth with respect the motor shaft and the different oscillation plane can therefore affect the vibrations transmitted to the hand-harm system.

Finally, bar angles and measurement points confirm the results of the whole analysis: no statistically significant differences among the bar angles and higher vibration for the hand which holds the bar (MP2) with respect that near the handgrip (MP1).

The first order interaction among harvesting heads, bars and measurement points are reported in Table 3.

They show that the bar B2 (carbon fibre) presents, on average, the lowest acceleration, whatever harvesting head. Moreover, the bars with greater diameter (B2 and B3, $40 \mathrm{~mm}$ ) produce higher vibrations in measurement point MP1, while that with smaller diameter (B1, 35 $\mathrm{mm}$ ) in MP2. This could be related to the different stiffness of the two types of bar, which affects the acceleration transmission towards the measurement points. Finally, the harvesting head H3 presents the highest difference between the two measurement points: $9.9 \mathrm{~m} / \mathrm{s}^{2}$ in MP1 and $21.9 \mathrm{~m} / \mathrm{s}^{2}$ in MP2 (median values).

\section{Field tests}

Acceleration data were analysed separately to compare laboratory $v s$ field tests for harvesting head $\mathrm{H} 3$ when used with the bars B1, B2 and B3. Being the bar angle not statistically significant, laboratory tests with different bar angles were treated as further replicates.

Comparing weighted global acceleration values for each bar type, measurement point, and test condition, the box plots reported in Figure 8 were obtained.

The differences among the three bars and between the two measurement points confirm the whole laboratory test results: the carbon fibre bar (B2) produces on average the lowest level of vibration $\left[12.0 \mathrm{~m} / \mathrm{s}^{2} \mathrm{vs}\right.$ 25.2 (B1) and 21.6 (B3), median values] and the vibration level in MP2 is higher than that in MP1 (21.8 vs $12.0 \mathrm{~m} / \mathrm{s}^{2}$, median values). Moreover, the bar B2 presents a more constant acceleration level: in fact, global RMS values ranges from 6.9 up to $20.4 \mathrm{~m} / \mathrm{s}^{2}$ (CV=27\%),

Table 3. First order interactions (median values, $\mathrm{m} / \mathrm{s}^{2}$ ).

\begin{tabular}{lccc} 
& \multicolumn{3}{c}{ Harvesting heads } \\
Bars & H1 & H3 \\
B1 & $19.5^{\mathrm{ab}}$ & $19.5^{\mathrm{a}}$ & $16.2^{\mathrm{ab}}$ \\
B2 & $19.4^{\mathrm{b}}$ & $17.7^{\mathrm{b}}$ & $12.6^{\mathrm{b}}$ \\
\hline B3 & $22.5^{\mathrm{a}}$ & $19.4^{\mathrm{b}}$ & $21.6^{\mathrm{a}}$ \\
Measurement points & $\mathrm{B} 1$ & Bars & \\
MP1 & $11.5^{\mathrm{b}}$ & $18.6^{\mathrm{a}}$ & $21.3^{\mathrm{a}}$ \\
MP2 & $27.1^{\mathrm{a}}$ & $16.0^{\mathrm{b}}$ & $20.9^{\mathrm{a}}$ \\
\hline & & Harvesting heads \\
Measurement points & H1 & H2 & H3 \\
MP1 & $22.5^{\mathrm{a}}$ & $18.3^{\mathrm{a}}$ & $9.9^{\mathrm{b}}$ \\
MP2 & $21.1^{\mathrm{a}}$ & $18.5^{\mathrm{a}}$ & $21.9^{\mathrm{a}}$ \\
\hline
\end{tabular}

Group separation by Kruskal-Wallis test for $\mathrm{P}$-level=0.05. Comparisons among bars for each harvesting head and between measurement points for each bar and harvesting head. H, head; B, bar; MP, measurement point; ab,ab values having a common letter are not significantly different at $\mathrm{P}$-level=5\%.

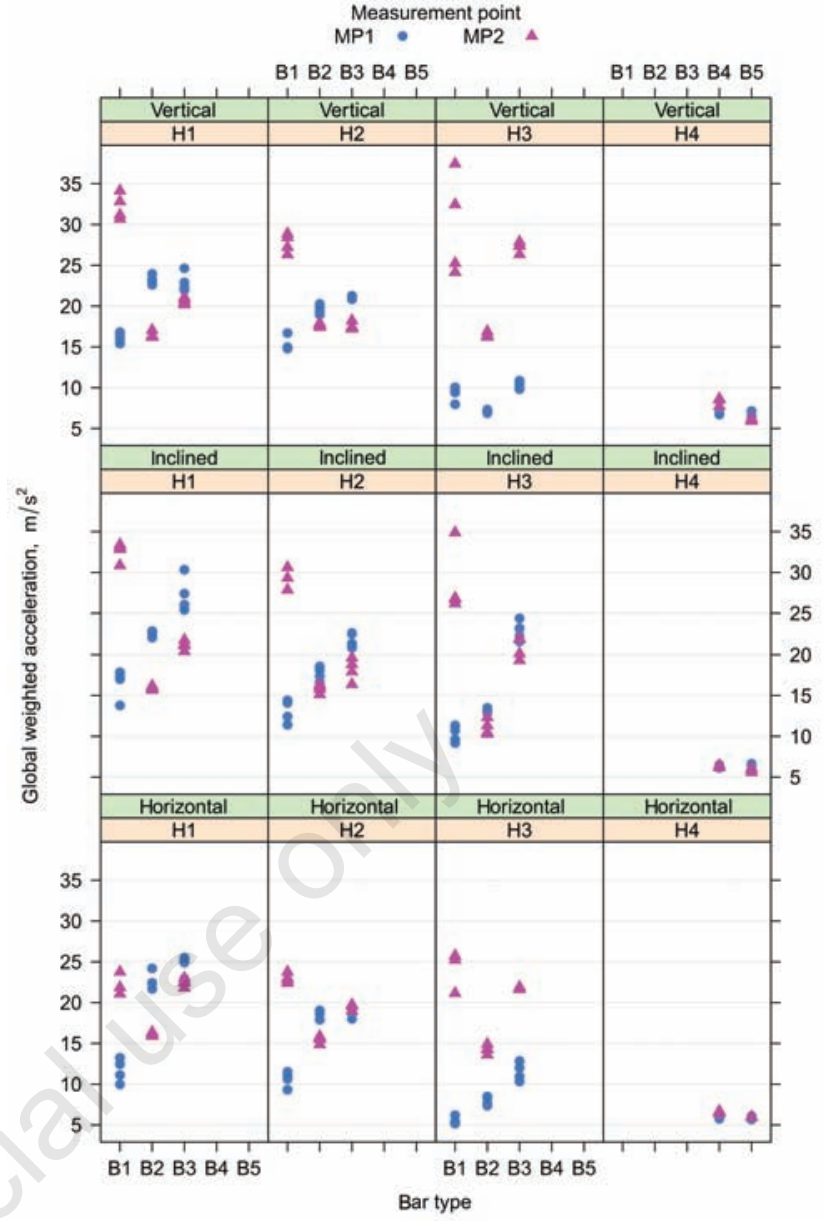

Figure 6. Global weighted acceleration values at varying harvesting head, bar type, bar angle and measurement point.

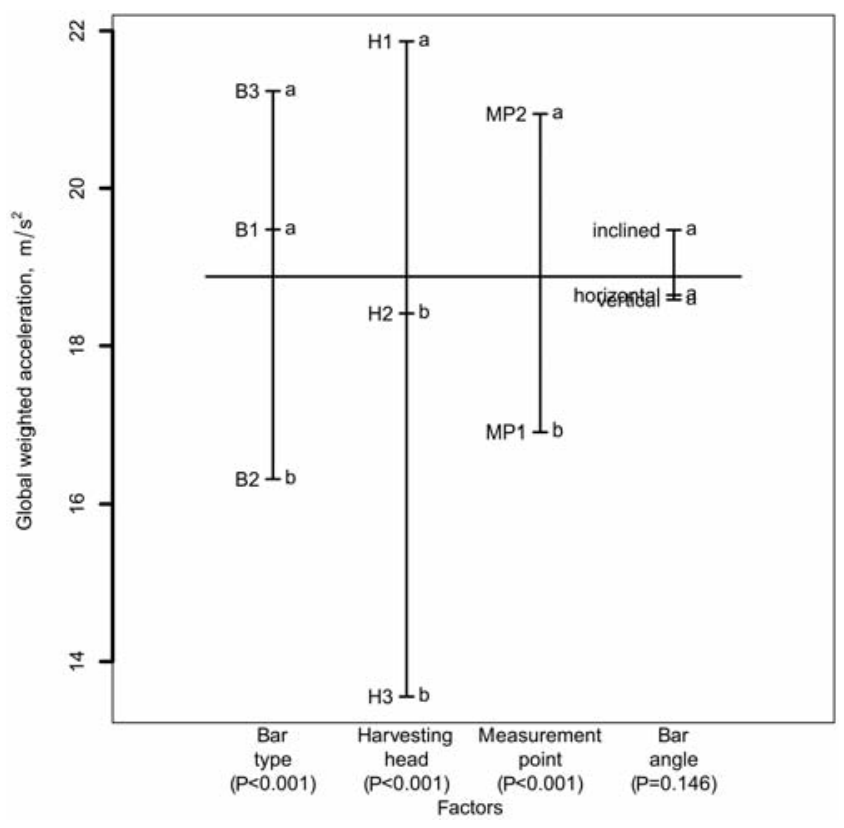

Figure 7. Plot design (median values) of the main factors related to bars $\mathrm{B} 1, \mathrm{~B} 2$ and $\mathrm{B} 3$ and harvesting heads $\mathrm{H} 1, \mathrm{H} 2$ and $\mathrm{H} 3$ (group separation by Kruskal-Wallis test for P-level=0.05). 
against the $5.2-37.4 \mathrm{~m} / \mathrm{s}^{2}$ of $\mathrm{B} 1(\mathrm{CV}=45 \%)$ and $9.8-32.6 \mathrm{~m} / \mathrm{s}^{2}$ of $\mathrm{B} 3$ $(\mathrm{CV}=29 \%)$. Finally, the difference between the two aluminium bars $\mathrm{B} 1$ and B3 is not statistically significant.

Comparing laboratory and field tests, the global weighted acceleration values increase from 13.6 up to $18.4 \mathrm{~m} / \mathrm{s}^{2}$ (median values). This means that the tree canopy has on average a negative effect on the vibrations transmitted to the hand-arm system, mainly due to the bar B1. In fact, analysing the first order interactions (Figure 9), it emerges that only the bar B1 (aluminium, $35 \mathrm{~mm}$ diameter) shows a significant difference between laboratory and field test. On the other hand, the bar B3 (aluminium, $40 \mathrm{~mm}$ diameter), produces in field and in laboratory comparable acceleration values, but higher than those produced by the bar B2 (carbon fibre, $40 \mathrm{~mm}$ diameter). This leads to the conclusion
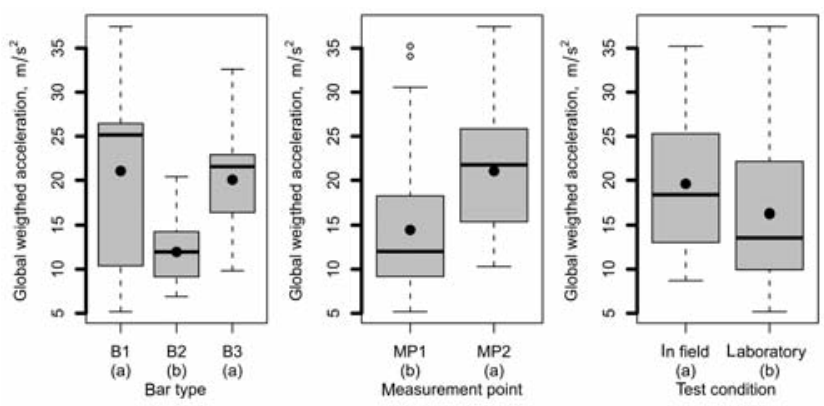

Figure 8. Global weighted accelerations values for each main factor; points represent mean values (group separation by KruskalWallis test at P-level=0.05).
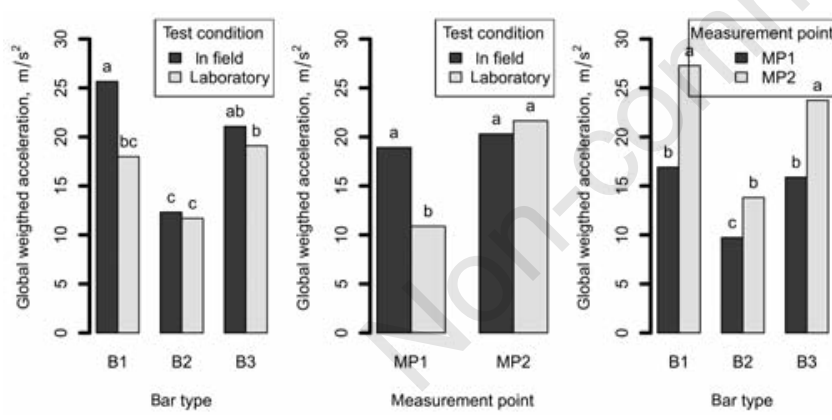

Figure 9. Global weighted accelerations for the first order interactions (median values, group separation by Kruskal-Wallis test at P-level=0.05).

Table 4. Global weighted acceleration values and signal length during the field tests.

\begin{tabular}{lcccc} 
Bar & MP1, m/s & Length, $s$ & MP2, m/s & Length, s \\
B1 & 26.78 & 729 & 26.89 & 241 \\
B2 & 10.56 & 418 & 13.74 & 602 \\
\hline B3 & 17.38 & 602 & 24.66 & 790 \\
\hline
\end{tabular}

B, bar; MP, measurement point. that the bar material plays the most important role in reducing the acceleration values, whereas the bar diameter mainly affects the comparison between no load and harvesting running. When comparing the measurement points, it emerges that, in MP2, the acceleration values are similar in both test conditions, whereas in MP1 they are significantly lower during laboratory tests. Probably the tree canopy, differently from the no load running, interferes with the flap oscillations, causing a greater transmission of the vibrations to the other bar extremity (MP1). Finally, looking at the interaction measurement point $\times$ bar type, it emerges that the vibration level in MP2 is always greater than that measured in MP1 for each bar.

The global weighted acceleration values obtained by analysing the whole signal during the field tests are reported in Table 4 .

They are little greater (from 0.7 up to $4.8 \%$ ) than those obtained by averaging the 1 min sub-samples. In all cases, they are much higher than the daily limit value $\left(2.5 \mathrm{~m} / \mathrm{s}^{2}\right)$ and the daily action value $(5.0$ $\mathrm{m} / \mathrm{s}^{2}$ ) established by the European Directive 2002/44/EC (European Commission, 2002). Considering the acceleration levels in the MP2 measurement point (the most exposed), the daily exposure times should range from 0.1 to $0.3 \mathrm{~h}$ when $\mathrm{A}(8)=2.5 \mathrm{~m} / \mathrm{s}^{2}$ and from 0.3 to 1.1 $\mathrm{h}$ when $\mathrm{A}(8)=5.0 \mathrm{~m} / \mathrm{s}^{2}$. These times are clearly incompatible with the length of a standard work-day in agriculture $(7 \mathrm{~h})$, so the use of antivibrating gloves, despite their limited effectiveness, and the reduction of exposure times through rotating shifts of the operators during the working day, should be recommended.

\section{Conclusions}

The research activity has pointed out that global acceleration levels transmitted to the hand-arm system by the tested portable harvesters are quite high (about $20 \mathrm{~m} / \mathrm{s}^{2}$ ), much higher than the limit or action values established by the European Directive 2002/44/EC (European Commission, 2002).

The vibration level is mainly affected by the kinematic system rather than the power source type: by adopting a harvesting head with two arms in opposite oscillations, it can be significantly lowered to about 6 $\mathrm{m} / \mathrm{s}^{2}$. A significantly reduction in vibration levels can be also obtained by adopting carbon fibre bars rather than aluminium ones: keeping constant the bar diameter $(40 \mathrm{~mm})$, the average acceleration, in laboratory conditions, decreases from 21 to $16 \mathrm{~m} / \mathrm{s}^{2}$. However this result should be investigated more in depth as the carbon fibre can change its mechanic specifications due to its production process. In like manner, aluminium bars may change their mechanical features at varying alloy and thickness. Therefore other bars of other manufacturers should be tested. When comparing laboratory (no load) and field tests (harvest under ordinary working conditions), acceleration levels increase, due to both canopy effect and force exerted by the operator. The greater differences between laboratory and field tests arise when aluminium bars of small diameter are used. This implies that laboratory tests are needed to characterise materials and machines in standard and controlled conditions. In all cases, operators should take responsibility for occupational health and safety, take safety precautions to reduce continuous vibration exposures over long periods, and arrange the work organisation so to include vibration-free periods. In fact, beside the use of antivibratory gloves, the best protection against vibrations lies in adopting working practices aimed at prevention. This aspect, unlike for industrial environments, is often underestimated among farmers, due to the variability of the working conditions. Being the use of portable harvesters for drupe harvesting limited in time along the year, the harvest capacity is the main characteristic that influences the purchase, while health and safety aspects are often neglected. 


\section{References}

Aldien Y., Marcotte P., Rakheja S., Boileau P.-É. 2006. Influence of hand forces and handle size on power absorption of the human handarm exposed to $z_{h}$-axis vibration. J. Sound Vib. 290:1015-39.

Besa A.J., Valero F.J., Suñer J.L., Carballeira J. 2007. Characterisation of the mechanical impedance of the human hand-arm system: the influence of vibration direction, hand-arm posture and muscle tension. Int. J. Ind. Ergonom. 37:225-31.

Biocca M., Fornaciari L., Vassalini G. 2008. Noise risk evaluation in electrical hand-held picking machines for olive harvesting. Proc. Int. Conf. Agr. Eng. "Agricultural and biosystems engineering for a sustainable world" June 23-25, Hersonissos, Crete, Greece, CDROM.

Blandini G., Cerruto E., Manetto G. 1997. Rumore e vibrazioni prodotti dai pettini pneumatici utilizzati per la raccolta delle olive. Proc. AIIA, September 11-12, Ancona, Italy, 4:229-38.

Burström L. 1997. The influence of biodynamic factors on the mechanical impedance of the hand and arm. Int. Arch. Occup. Environ. Health. 69:437-46.

Çakmak B., Saraço lu T., Alayunt F.N., Özarslan C. 2011. Vibration and noise characteristics of flap type olive harvesters. Appl. Ergonom. 42:397-402.

Caruso L., Cerruto E., Manetto G., Schillaci G. 2005. Facilitated harvesting of drupaceous: mechanisation and ergonomic analysis. Proc. VIII Natl. Congr. Ita. Assoc. Agr. Eng., June 27-30, Catania, Italy, CDROM.

Cerruto E., Manetto G., Schillaci G. 2010. Vibrations produced by electric shakers for olive harvesting. Proc. Int. Conf. "Work Safety and Risk Prevention in Agro-lood and Forest Systerns", September 1618, Ragusa, Italy, CD-ROM.

Cerruto E., Manetto G., Schillaci G. 2011. Vibrations transmitted to the hand-arm system by electric shakers during olive harvesting. Proc. Int. Conf. XXXIV CIOSTA-CIGR V "Efficient and sale production processes in sustainable agriculture and forestry", June 29-July 1, Vienna, Austria, CD-ROM.

Chetter I.C., Kent P.J., Kester R.C. 1998. The hand arm vibration syndrome: a review. Cardiovasc. Surg. 6:1-9.

Concettoni E., Griffin M. 2009. The apparent mass and mechanical impedance of the hand and the transmission of vibration to the fingers, hand, and arm. J. Sound Vib. 325:664-78.

Deboli R., Calvo A., Preti C. 2008. The use of a capacitive sensor matrix to determine the grip forces applied to the olive hand held harvesters. Proc. Int. Conf. "Innovation Technology to Empower Safety, Health and Welfare in Agriculture and Agro-food Systems", September 15-17, Ragusa, Italy, CD-ROM.

Dewangan K.N., Tewari V.K. 2008. Characteristics of vibration transmission in the hand-arm system and subjective response during field operation of a hand tractor. Biosyst. Eng. 535-46.

Dong R.G., McDowell T.W., Welcome D.E., Smutz W.P. 2005. Correlations between biodynamic characteristics of human hand-arm system and the isolation effectiveness of anti-vibration gloves. Int. J. Ind. Ergonom. 35:205-16.

Dong R.G., Schopper A.W., McDowell T.W., Welcome D.E., Wu J.Z., Smutz W.P., Warren C., Rakheja S. 2004. Vibration energy absorption (VEA) in human fingers-hand-arm system. Med. Eng. Phys. 26:483-92.

European Commission. 2002. European Directive of 25 June 2002 on the minimum health and safety requirements regarding the exposure of workers to the risks arising from physical agents (vibra- tion), 2002/44/EC. In: Official Journal, L 177/13, 06/07/2002, pp .

Famiani F., Giurelli A., Proietti P., Nasini L., Farinelli D., Guelfi P. 2008. Sì alla raccolta agevolata in oliveti tradizionali ed intensivi. L'Informatore Agrario 4:103-7.

FAO (Food and Agriculture Organization). 2010. Food and agricultural commodities production. Available from: http://faostat.fao.org/ site/339/default.aspx

Griffin M. 2008. Measurement, evaluation, and assessment of peripheral neurological disorders caused by hand-transmitted vibration. Int. Arch. Occup. Environ. Health. 81:559-73.

Iannicelli V., Ragni L. 1994. Agevolatrici vibranti per la raccolta delle olive. Riv. Ing. Agr. 25:248-56.

IOC (International Olive Council). 2011. Olive oils production. Available from: http://www.internationaloliveoil.org/estaticos/ view/131-world-olive-oil-figures

ISMEA (Istituto di Servizi per il Mercato Agricolo Alimentare). 2012. Il mercato internazionale e nazionale dell'olio d'oliva. Available from: http://www.ismea.it/flex/cm/pages/ServeBLOB.php/L/T/IDPagina/7 051

ISO, 2004. Mechanical vibration measurement and evaluation of human exposure to hand-transmitted vibration - part 1: general requirements. Norm IS0 5349-1:2004. International Organization for Standardization Publ., Geneva, Switzerland.

ISTAT (The National Institute for Statistics). 2010. Superfici e produzioni: olio, olive da tavola, olive da olio, olio di pressione. Available from: http://agri.istat.it/jsp/dawinci.jsp?q= plC27000001 0000012000\&an=2010\&ig=1\&ct=311\&id=21A\%7C15A\%7C32A

Italian Regulation. 2005. Attuazione della direttiva 2002/44/CE sulle prescrizioni minime di sicurezza e di salute relative all'esposizione dei lavoratori ai rischi derivanti da vibrazioni meccaniche, LD 187/2005. In: Gazzetta Ufficiale no. 220, 21/09/2005, pp 7-11.

Italian Regulation. 2008. Attuazione dell'articolo 1 della legge 3 agosto 2007 , n. 123 , in materia di tutela della salute e della sicurezza nei luoghi di lavoro, LD 81/2008. In: Gazzetta Ufficiale no. 101, 30/04/2008, suppl. ordinario n. 108.

Mallick Z. 2010. Optimization of the operating parameters of a grass trimming machine. Appl. Ergonom. 41:260-5.

Monarca D., Cecchini M., Colantoni A. 2007. Study for the reduction of vibration levels on an "Olive electrical harvester". Proc. XXXII CIOSTA-CIGR Sect. V Conf., September 17-19, Nitra, Slovakia, Part II:503-9.

Monarca D., Cecchini M., Vassalini G. 2003. Vibrations transmitted to hand-arm by the main chainsaws models sold in the Italian market. Riv. Ing. Agr. 1:53-64.

Pascuzzi S., Santoro F., Panaro V.N. 2008. Study of workers' exposures to vibrations produced by portable harvesters. Proc. Int. Conf. "Innovation Technology to Empower Safety, Health and Welfare in Agriculture and Agro-food Systems", September 15-17, Ragusa, Italy, CD-ROM.

R Development Core Team, 2007. R: A language and environment for statistical computing. R Foundation for Statistical Computing, Vienna, Austria. Available from: http://www.R-project.org

Ramos D., Schoenmann L., Scott D., Trent J. 1996. The effects of vibration on workers. Work 6:127-32.

Tewari V.K., Dewangan K.N. 2009. Effect of vibration isolators in reduction of work stress during field operation of hand tractor. Biosyst. Eng. 103:146-58.

Vergara M., Sancho J.-L., Rodríguez P., Pérez-González A. 2008. Handtransmitted vibration in power tools: Accomplishment of standards and users' perception. Int. J. Ind. Ergonom. 38:652-60. 